\title{
Nurturing 21st century physician knowledge, skills and attitudes with medical home innovations: the wright center for graduate medical education teaching health center curriculum experience
}

Linda Thomas-Hemak, Ghanshyam Palamaner Subash Shantha, Lakshmi Rani Gollamudi, Jignesh Sheth, Brian Ebersole, Katlyn J. Gardner, Julie Nardella, Meaghan Ruddy, Lauren Meade

Purpose: Effect of patient centered medical home (PCMH) curriculum interventions on residents' self-reported and demonstrated knowledge, skills and attitudes in PCMH competency arenas (KSA) is lacking in the literature. This study aimed to assess impact of PCMH curricular innovations on Internal Medicine residents' KSA. Methods: Twenty four (24) Internal Medicine residents - 12 Traditional (TR) track and 12 Teaching Health Center (THC) track - began training in academic year (AY) 2011 at the Wright Center for Graduate Medical Education (WCGME). They were followed through AY2013 covering three years of training. PCMH curricular innovations were applied beginning July 2011 until May 2012 focally to THC residents. These curricular innovations were spread program wide in May 2012. Semi-annual, validated PCMH Clinician Assessments assessing KSA were started in AY2011 and completed by all residents. Results: Mean KSA scores of TR residents were similar to THC residents at baseline for all PCMH competencies. In May 2012, mean scores of THC residents were significantly higher than TR residents for most KSA. After program wide implementation of PCMH innovations, mean scores of TR residents for all KSA improved and most equalized to those of THC residents. Globally improved KSA scores of THC and TR residents were maintained through May 2014, with the majority of improvements above baseline reaching statistical significance. Conclusions: PCMH curricular innovations inspired by Health Resources and Services Administration (HRSA's) Teaching Health Center funded residency program expansion quickly and consistently improved Internal Medicine residents' KSA. 
2 Authors: Linda Thomas-Hemak MD, FACP, Ghanshyam Palamaner Subash Shantha MD, MPH,

3 Lakshmi Rani Gollamudi MD, Jignesh Sheth MD, MPH, Brian Ebersole, Katlyn J. Gardner, Julie

4 Nardella, PhD, MSN/Ed, RN, Meaghan Godwin, MA, PhD, Lauren Meade MD, FACP

5 Dr. Linda Thomas-Hemak MD is the President and Chief Executive Officer of the Wright Center for

6 Graduate Medical Education and the Program Director for the Internal Medicine residency training

7 program.

8 Dr. Ghanshyam Palamaner Subash Shantha MD, MPH is a teaching health center resident in the

9 Internal Medicine residency training program at the Wright Center for Graduate Medical Education,

10 Scranton, PA.

11 Dr. Lakshmi Rani Gollamudi MD is a teaching health center resident in the Internal Medicine

12 residency training program at the Wright Center for Graduate Medical Education, Scranton, PA.

13 Dr. Jignesh Sheth MD, MPH is the Vice President for Accountability and Measurement as well as an

14 attending physician in the Internal Medicine residency program at the Wright Center for Graduate

15 Medical Education, Scranton, PA

16 Brian Ebersole is the Senior Vice President for Mission Delivery at the Wright Center for Graduate

17 Medical Education, Scranton, PA.

18 Katlyn J. Gardner is the Residency Program Supervisor at the Wright Center for Graduate Medical

19 Education, Scranton, PA

20 Dr. Julie Nardella, PhD, MSN/Ed, RN is the Education and Community Relevance Leader at the

21 Wright Center for Graduate Medical Education in Scranton, PA. 
22 Dr. Meaghan Godwin, MA, PhD is Director of Transformative Education at the Wright Center for

23 Graduate Medical Education, Scranton, PA

24 Dr. Lauren Meade MD, FACP is Associate Professor of Medicine at Tufts Medical School, Macy

25 Faculty Scholar at Baystate Health, Springfield, Massachusetts and Director of Faculty Engagement

26 and Development at The Wright Center for Graduate Medical Education, Scranton, PA.

27 Disclosure of funding: The Wright Center for Graduate Medical Education Consortium's Internal

28 Medicine residency is funded directly through HRSA Teaching Health Center and Veteran Hospital

29 GME funding as well as through CMS funded hospitals' affiliations.

30 Word count: 3495

31 Address of correspondence and requests for reprints:

32 Dr. Linda Thomas-Hemak, MD

33 President and CEO, The Wright Center for Graduate Medical Education

34501 Madison Ave, Scranton, PA 18510, (O) 570-343-2383 ext 2301

35 Email: thomas1@thewrightcenter.org

36

37

38

39 INTRODUCTION: 
40 The 21 st century marks a period of dramatic shift in health care paradigms in the United States. Health

41 care costs in the United States have grown exponentially [1], but are not paralleled by improvements in

42 health care delivery efficiencies, public health outcomes, physician skill development or patient

43 satisfaction with health care experiences [2,3]. Patient centered medical home (PCMH) shows

44 promise as a quality, team based and population health focused model of innovative primary care

45 delivery that may potentiate value enhancement in health care delivery with reduction in costs and

46 improved health outcomes $[4,5,6]$. PCMH enthusiasm has prompted many professional organizations,

47 stakeholders, and policy-makers [7] to work at national, state, and local levels to ensure integration of

48 this innovative strategy in primary care practices and promote pursuit of National Committee for

49 Quality Assurance (NCQA) PCMH certification. Ongoing systems of measurement and process

50 change in support of the implementation of high PCMH standards can enhance quality, cost-

51 effectiveness and outcomes-focused care [8,9].

Authentic transformation of health care delivery models requires a change in the skill sets of

53 primary care providers $[10,11,12,13,14]$. In a study by Kaiser Permanente, skill sets of routine

54 office-based competencies including chronic disease management, care coordination, care continuity,

55 familiarity with team-based care models, clinical information technology, leadership and management

56 skills, and systems thinking were reported as deficient in newly trained physician workforce [15].

57 Responsively, various components of the Affordable Care Act legislation have aimed to address the

58 national shortage and mal-distribution of physicians, to inspire new skill sets production and to reduce

59 related health disparities. One legislative example is the Teaching Health Center Graduate Medical

60 Education (THCGME) Program implemented by the Health Resources and Services Administration

61 (HRSA). In 2011, THCGME pioneering grantees included nine Family Medicine, one dental and one

62 Internal Medicine residencies [17, 18]. The Wright Center for Graduate Medical Education (WCGME) 
63 is the sponsoring institution for the ACGME accredited Internal Medicine residency in the initial 64 cohort of THCGME programs.

WCGME sought to align educational processes with reform mandates, THCGME funding

66 intent and local community need. The resulting comprehensive curricular redesign increased training

67 time in ambulatory care settings including Federally Qualified Health Center (FQHC) exposure,

68 provided focused PCMH and leadership didactics and aligned engagement in ambulatory care based

69 continuous quality improvement projects. This study provides evidence of changes in residents' KSA

70 in support of the teaching health center based curriculum. This curriculum aligns graduate medical

71 education with the complexities of health care reform and patient care needs.

\section{MATERIALS AND METHODS:}

73 On approval of this prospective cohort study by the Institutional Review Board of the Wright Center,

74 informed consent was obtained from each participating resident. Measures were implemented to

75 ensure anonymity of resident participants and assessment data they provided throughout the study

76 duration. Since AY 2011, all Internal Medicine residents completed semi-annual PCMH Clinician

77 Assessments, as well as other data collection tools.

78 Setting: PCMH based didactics enhancements and resident engagement in reflective continuous

79 quality improvement (CQI) within ambulatory venues with or pursuing National Committee for

80 Quality Assurance (NCQA PCMH certification were focally applied to 2011 Teaching Health Center

81 (THC) track residents from training initiation in July 2011. In May 2012 these changes were spread

82 program wide. Innovations specifically applied to THC residents from the start of training also

83 included increased block continuity clinic exposure split between a Wright Center for Primary Care

84 (WCPC) and a proximal FQHC with an intentional ratio of 50\% ambulatory and 50\% hospital based 
85 rotations. In contrast, Traditional (TR) track residents continued with historical half day/week 86 continuity clinic exclusively at WCPC and had 30\% ambulatory and 70\% hospital based rotation

87 exposure. Continuity ambulatory and hospital rotational exposure models remained different between 882011 THC and TR training tracks of study participants for the entire three years.

Participating Residents: WCGME recruited 12 THC and 12 TR residents to start Internal Medicine training in AY2011. Those reporting definitive interest in ambulatory medicine were assigned to the THC track and those uncertain or interested in hospitalists or specialty careers were randomly assigned to the THC or TR track. One 2011 THC resident left the program in January 2014 and one 2011 THC resident had a 3 month training delay who graduated off cycle in September 2014. During the study period, 10 and 12 TR residents, who started training in 2009 and 2010 respectively, completed training and graduated (2009 and 2010 TR Graduating Seniors).

PCMH Curricular Innovations: A detailed explanation of the curriculum is provided at http://www.thewrightcenter.org/graduate-medical-education/residency/allopathic-internal-medicine/. In addition to increased and FQHC expanded block based continuity clinic exposure, THC residents were exposed to enhanced PCMH based didactics, clinic team huddles and CQI ambulatory projects. Weekly team huddles identified care delivery deficits for which THC residents helped design and implement team based remediations. As part of Pennsylvania Academy of Family Practice's Improving Performance in Practice Residency Program/Community Health Center Collaborative, residents engaged in team based CQI projects. They also participated in monthly team calls and quarterly learning sessions. The didactic curriculum was augmented to include weekly PCMH based interactive sessions for THC track residents including topics on PCMH delivery model, Quality Improvement fundamentals, Population Management, EMR Meaningful Use, Team Skills and Leadership. 
108 2012, these didactic interventions were applied focally only to THC residents. Because THC residents

109 consistently outperformed TR cohort colleagues and TR 2009 Graduating Senior Residents in most

110 KSA by end of AY2011, PCMH curricular innovations were spread program wide beginning in May

111 2012. Future AY recruits were all integrated into the new, balanced THC clinical exposure model with

112 block ambulatory time spilt between a Wright Center for Primary Care and proximal FQHC.

113 Mandatory clinical training curricular enhancements in Women's Health, Oral Hygiene and Primary

114 Care Psychiatry were added in AY2012 only for THC residents.

115 Assessment details: Demographic details including age, gender, country of origin, prior residency 116 training, completion of other advanced degrees such as masters of public health (MPH) or doctoral 117 degrees, prior US clinical experience, prior research experience and year of medical school graduation 118 were compared between 2011 THC and TR residents at baseline. Semi-annual November and May 119 validated PCMH Clinician Assessments were completed by all Internal Medicine residents at WCGME 120 since 2011. This PCMH Clinician Assessment assesses nine KSA: 1) Team Approach: the utilization 121 of physician-led team-based health care delivery that has all members practicing at the highest level of 122 their license to engage patients and optimize care, 2) Information System Support: encompasses 123 meaningful use of electronic medical records as well as accurate, timely and effective flow of 124 information between health care delivery stakeholders that assures ready access to key data on 125 individual patients and the overall population. 3) Self-Management Support: acknowledgement of the 126 patients' central role in their care, one that fosters a sense of responsibility for their own health and 127 resiliency. Using a collaborative approach, providers and patients work together to define problems, set 128 priorities, establish obtainable goals, create treatment plans and solve problems along the way, 4) Use 129 of Guidelines: clinical decision making to promote utilization of evidence in facilitating shared- 
130 decision making between the care team and the patients, 5) Quality Improvement: systematic approach

131 to the reduction and elimination of waste, rework and losses in production encouraged by reflective 132 practice for improvement and just-in-time alterations of health care delivery, 6) Population

133 Management: management of the health outcomes of a group of individuals, including the distribution

134 of such outcomes within the group. It is an approach to health that aims to improve the health of an

135 entire population served, 7) Care Coordination: deliberate organization of patient care activities across

136 the care continuum to reduce duplicative efforts and achieve better outcomes, 8) Patient Centered Care:

137 providing care that is respectful of and responsive to individual patient preferences, needs, and values,

138 and ensuring that patient values guide all clinical decisions, and 9) Treatment of Mental Health Issues:

139 integration of screening and mental health care referral/provider services into the primary care

140 processes realizing it is the first line of defense for the diagnosis, treatment and prevention of mental

141 health issues. . Each assessment question has self-rated score options from 1-5, with 1 denoting limited

142 and 5 denoting superior competency. This survey tool was developed and used by Jortberg et. al [13] to

143 assess family medicine residents' KSA. A copy of the survey tool can be found in the supplemental file 144 titled 'sample survey' and also by following the web link 145 http://pcmhelearning.com/theme/intervision_custom/pdf/PCMH.CA.pdf. As described by Jortberg et. al.

146 [13], a previous version of this tool has been used to assess clinician reported use of elements of 147 chronic care model in primary care setting [18, 19]. To this previous version Jortberg et. al. [13] added 148 components to satisfy KSA and used it in their study on family medicine residents. We used the same 149 survey tool from the paper by Jortberg et. al [13] and used it to assess our IM residents' KSA. The 150 Cronbach's alpha assessing reliability for each of the PCMH competencies in the survey tool were > $151 \quad 0.8$. 
The analysis focused on the 2011 cohort of THC and TR Residents (12 in each group) as a

153 comparative platform to assess historical and new curricular innovations. In total, 2011 THC and TR

154 residents completed six assessments from November 2011 thru May 2014. We compared four 155 assessments longitudinally within and between the 2011 THC and TR tracks from the following time 156 points: 1) Baseline Assessment (November 2011); 2) End of first training year (May 2012); 3) Second 157 year of training (November 2012); 4) Graduation assessment near training completion (May 2014). 2011 THC and TR residents' scores in May 2012 and near graduation in May 2014 were also 159

160 years. Rationale for this analysis is that 2009 and 2010 TR Graduating Seniors were trained prior to 161 implementation of THC PCMH innovations, noting that 2009 TR graduates had no direct exposure to 162 curricular innovations described and 2010 TR graduates had one year of exposure after program wide 163 rollout of curricular innovations. The 2009 and 2010 TR trainees completed two and four PCMH 164 Clinician assessments respectively.

\section{STATISTICAL ANALYSIS:}

166 Data was expressed as mean \pm standard deviation for continuous variables and number (\%) for 167 categorical variables. Data distribution normality was assessed using the Kolmogorov-Smirnov test. 168 Considering small sample sizes, our data were predominantly non-normally distributed so non169 parametric tests were used for all comparisons. Due to non-parametrically distributed data, continuous 170 variables were compared between groups using Wilcoxon rank sum test. Categorical variables were 171 compared between groups using chi-squared test. Mean group based scores for KSA assessed were 172 compared longitudinally for both 2011 THC and TR residents over 3 years of training at the above 173 defined time points, with comparisons to just prior and baseline scores. Between groups cross-sectional 
174 comparisons of mean individual and global KSA scores at the defined time points were done for 2011

175 THC and TR cohort residents. Similar between group cross sectional comparisons for each 2011

176 cohort's mean individual and global scores in May of their internship and graduation year were also

177 done with near graduation May surveys of 2009 and 2010 TR residents in their respective graduation

178 year. All analyses were performed using STATA 11 statistical software. P $<0.05$ was considered

179 statistically significant.

\section{RESULTS}

181 Response rates for all assessments were 100\%. Demographic comparisons detailed in Table 1 showed 1822011 THC residents were older and completed medical school earlier than TR resident peers (Table 1).

183 Gender distribution, country of origin, prior residency training, advanced degrees, prior US clinical and 184 research experiences were similar (Table 1).

185 Longitudinal within Groups 2011 THC and TR Residents Comparison: Compared to November 1862011 baseline, May 2012 THC residents' assessments showed mean score improvement for all KSA 187 except Patient Centered Care. THC mean scores for all individual and global KSA improved from 188 baseline on the May 2014 assessments, with majority of improvements reaching statistical significance. 189 (Table 2) Unlike THC peers, TR residents' mean scores in May 2012 remained similar to November 1912011 baseline without improvement for most KSA. May 2014 TR scores did show significant 192 improvement in all KSA with improvements above baseline for Team Approach, Self-Management 193 Support, Quality Improvement, Population Management and Treatment of Mental Health Issues 194 reaching statistical significance. (Table 3) 
195 Between Groups 2011 THC and TR Residents Comparison: Baseline assessments showed similar

196 performance in all KSA when 2011 THC residents were compared to 2011 TR peers (Table 4). May

1972012 assessments showed 2011 THC residents consistently scored higher in most and global KSA than

198 TR peers and 2009 TR Graduating Seniors (Table 4; Figure 1, Supplemental Table 1; Supplemental

199 Figure 1). Because of notable May 2012 performance improvement of 2011 THC residents in most 200 KSA above baseline and superior performance above 2011 TR peers and 2009 TR Graduating Seniors, 201 PCMH curricular innovations were spread program wide at this time. However to preserve continuity 202 exposure, the redesigned training model of increased block based ambulatory continuity split between 203 a WCPC and proximal FQHC was not spread program wide at this time as program leadership opted 204 for phased roll out for this training model for all new interns starting in AY2012.

The November 2012 KSA assessment completed six months after program-wide spread of 206 PCMH curriculum innovations revealed 2011 TR residents showed global but not statistically significant improvement in KSA from baseline. However,TR mean scores did equalize for all KSA 208 with THC colleagues at this time and remained comparable to THC peers through May 2014. (Figure 209 1, Table 4) 2011 THC residents mean scores for most KSA in May 2014 were consistently better for most 211 and global KSA than 2009 TR Graduating Seniors in May 2012 with 5 of 9 KSA improvements 212 reaching statistical significance. (Supplemental Table 2; Supplemental Figure 2) Similar to THC peers, 213 near completion of their training in May 2014, 2011 TR residents scored significantly higher in 4 of 9 214 KSA compared to the May 2012 assessment completed by 2009 graduating TR seniors. (Supplemental 215 Table 3) Notably, both 2011 THC and TR mean scores in May 2014 were essentially similar to May 2162013 scores on near graduation May assessments completed by 2010 TR graduating seniors 
217 (Supplemental Table 2, 3; Supplemental Figure 3, 4), the latter of whom did have one year of direct 218 exposure to PCMH curriculum innovations in their senior year.

\section{DISCUSSION:}

220 Our study shows that multi-dimensional PCMH based curricular innovations in the WCGME's Internal 221 Medicine residency significantly enhanced THC residents' KSA by the end of their internship year and 222 that these improvements over baseline were maintained through three years of training. Subsequent 223 program wide implementation of PCMH curricular innovations in May 2012 enhanced KSA in both 2242011 and 2009 TR residents as well within a similar timeframe.

Effect of PCMH innovations on patient outcomes, care delivery organizational structure and cost effectiveness have been debated in the literature [21 - 24]. Hochman et. al [24] showed that after one year of PCMH interventions, using NCQA's PCMH certification tool, residents' satisfaction with experience of patient care improved significantly with enhanced perception that patients received comprehensive care at their facility. However, the effect of PCMH curricular innovations on KSA is scant. Our study provides evidence that intentional PCMH curricular innovations can improve residents' self-reported KSA in arenas reported as deficient in Kaiser Permanente's survey [15]. center exposure during three years of residency training, our program was sensitive to the potential 234 distraction from the traditional Internal Medicine residency training focus that ensures broad, specialty specific medical knowledge acquisition. Prior research [25] compared our 2011 THC and TR residents'

236 first In-Training Exam (ITE) performance, an objective metric assessing comprehensive Internal 237 Medicine medical knowledge. In this assessment, 2011 THC residents performed similar to TR counterparts in all specialties except for slight underperformance in Pulmonary/Critical Care Medicine. 
239 Notably, 2011 THC residents performed significantly better than TR peers in Endocrinology ( $P=$ 240 0.021) [25]. Presumed due to exposure to diabetes care as a ubiquitous PCMH target population, this 241 potential to increase Endocrinology knowledge offers promise in enhancing physician knowledge to 242 counter our national diabetes epidemic. We realize the need for KSA to parallel objective testimonials

243 from faculty physicians, peers, staff and patients directly observing our residents in patient care venues.

244 In the supplemental file, we have detailed an analysis where we assessed the six (6) core competencies 245 of the Accreditation Council for Graduate Medical Education (ACGME) for these 24 residents. This 246 analysis of ACGME core competency based evaluations, an objective assessment to confirm enhanced 247 skills, showed that 2011 THC and TR residents improved their mean scores for ACGME core 248 competencies by December 2012 and sustained these improvements until completion of their training 249 in June 2014 (Supplemental Analysis and Supplemental Tables 4 - 14). The ACGME core 250 competencies were mapped to KSA and several linked scores compared showed positive correlations 251 for both 2011 THC and TR residents by December 2012. These correlations were sustained until June 2522014 (Supplemental Analysis and Supplemental Tables 4 - 14). This analysis suggests that PCMH 253 curricular innovations in addition to improving KSA also enhanced residents' directly observed skill 254 sets for effective patient care delivery in the PCMH model evidenced within an ACGME core 255 competency framework.

Though earlier small sample studies showed enhanced patient outcomes with the PCMH model 257 [20,21], a recent large study by Friedberg et al [22] showed limited improvement in quality and no 258 improvement in health care utilization or cost effectiveness among multiple practices that adopted this 259 model for three years, suggesting further refinement is necessary in PCMH interventions [22].

260 Financial sustainability of PCMH interventions in current form is unknown. As a result, PCMH model 261 modifications are probable in the future. Creation of a physician workforce with deeper understanding 
262 of core PCMH principles offers promise to make knowledgeable and adaptable physician leaders

263 prepared to lead PCMH evolution to promote ongoing care delivery transformation in pursuit of the

264 Institute for Healthcare Improvement's Triple Aim - improved quality, better outcomes and lower cost.

\section{Limitations}

266 Our study had advantages of prospective design and follow-up through the three year training cycle of 267 23/24 engaged 2011 THC and TR residents with a consistent 100\% response rate. Small sample size 268 was a limiting factor precluding multivariate comparisons and control for obvious confounders 269 including higher age and longer length of time since medical school graduation in 2011 THC residents. 270 Admittedly, our methods only assessed KSA which have not been causally linked to demonstration of 271 these competencies in patient care delivery or actuated improvements in health outcomes. However, we 272 did find that these improvements in KSA correlate positively with testimonials confirming 273 improvement in ACGME core competencies. There remains a need to further explore the relationship 274 between enhanced KSA with enhanced patient care delivery processes and health outcomes 275 demonstrated in the ACGME's Next Accreditation System framework for educational outcomes. Method of recruitment based on THC track self-selection may have added selection bias as 277 primary care focused Internal Medicine residents who chose the THC track may have been more 278 oriented and committed to developing KSA. However, this selection bias seems unlikely given similar 279 baseline assessment scores for THC and TR residents. Additionally, after program wide 280 implementation of PCMH based curricular innovations, even without change in TR half day continuity 281 clinic/week and 30\% ambulatory/70\% hospital based rotational exposure, 2011 TR residents and 2010 282 graduating TR seniors showed similar improvement in most KSA. 
Cross track diffusion of didactic and CQI exposure enhancements by peer to peer education and

284 program wide PCMH based curricular innovations in AY2012 may have diluted detectable

285 comparative effectiveness of the innovations on training track cohorts. Finally, contemporary clinical

286 learning environment exposure of TR residents during half day and one block continuity clinic rotation

287 to THC residents well acclimated to ambulatory learning venues may have also diluted detectable

288 effectiveness of curricular interventions.

\section{Conclusions}

290 HRSA's THCGME funding catalyzed curricular innovations in The Wright Center's Internal Medicine

291 Residency program. These innovations increased and enhanced PCMH based didactics, engagement in 292 ambulatory based CQI projects, and training time in ambulatory care centers. PCMH curricular 293 innovations were associated with enhanced KSA and demonstrated improvements in ACGME core 294 competencies. Improvements occurred within six months and were replicated after curriculum spread 295 within the same timeframe to TR residents despite their continuing in the historical training model of 296 half day weekly continuity clinics with $30 \%$ ambulatory and $70 \%$ hospital based training exposure.

Notable improvements in KSA above baseline and compared to prior 2009 TR graduates were sustained over three years of training. A large study assessing the expanded correlation of KSA with ACGME core competency-based global 360 evaluations, as well as patient care delivery process and

300 health outcomes, are required before firm inferences can be made from our results. The Next

301 Accreditation System offers a relevant, data-driven roadmap of educational and patient care outcomes

302 for these validations. Overall, The Wright Center's THC Consortium's Internal Medicine residency

303 program inspires hope for a better prepared $21^{\text {st }}$ century physician workforce than previously reported

304 by Kaiser Permanente in 2011 [15]. 
305 Other disclosures: None to disclose

306 Ethical approval: Ethical approval was waived after review by the Institutional Review Board of the

307 Wright Center for Graduate Medical Education, Scranton, PA on the $17^{\text {th }}$ September 2013.

308 Disclaimer: No disclaimers

309 Previous presentations: Results of the first year were presented at Regional American College of

310 Physicians' Poster Session in April 2013 and at the National Association of Community Health

311 Centers' (NACHC) Community Health Institute Poster Session in August 2013.

312

313

314

315

316

317

318

319

320

321

322 


\section{References}

1) Martin A, Lassman D, Whittle L, Catlin A; National Health Expenditure Accounts Team.

Recession contributes to slowest annual rate of increase in health spending in five decades. Health Aff (Millwood). 2011;30:11-22.

2) McGlynn EA, Asch SM, Adams J, Keesey J, Hicks J, DeCristofaro A. The quality of health care delivered to adults in the United States. N Engl J Med. 2003;348:2635-2645.

3) Wilensky GR, Berwick DM. Reforming the Financing and Governance of GME. N Engl J Med. 2014. 371:792-793.

4) Agency for Healthcare Research and Quality. Patient Centered Medical Home Resource Center. (http://pcmh.ahrq.gov/). Accessed January 24, 2011.

5) Scholle S, Torda P, Peikes D, Han E, Genevro J. Engaging Patients and Families in the Medical Home (Prepared by Mathematica Policy Research under contract no. HHSA290200900019ITO2.) AHRQ Publication no. 10-0083-EF. Rockville, MD: Agency for Healthcare Research and Quality; June 2010 .

6) Stange KC, Nutting PA, Miller WL, Jaen CR, Crabtree BF, Flocke SA. Defining and measuring the patient-centered medical home. J Gen Intern Med. 2010;25:601-612.

7) Joint principles of the patient-centered medical home. American Academy of Family Physicians, American Academy of Pediatrics, American College of Physicians, American Osteopathic Association. 
(http://www.acponline.org/running_practice/delivery_and_payment_models/pcmh/demonstrations/ jointprinc_05_17.pdf). Accessed January 5, 2014.

8) Bitton A, Martin C, Landon BE. A nationwide survey of patient centered medical home demonstration projects. J Gen Intern Med. 2010;25:584-592.

9) Patient centered medical home resource center: catalogue of federal PCMH activities. Agency for Healthcare Research and Quality. (http://pcmh.ahrq.gov/page/federal-pcmh-activities/html). Accessed January 5, 2014.

10) Bowen JL. Stevens DP, Sixta CS, Provost L, Johnson JK, Woods DM, Wagner EH. Developing Measures of Educational Change for Academic Health Care Teams Implementing the Chronic Care Model in Teaching Practices. J Gen Intern Med. 2010;25(Suppl 4):586-592.

11) Johnson J K, Woods DM, Stevens DP, Bowen JL, Provost LP, Sixta CS, Wagner EH. Joy and Challenges in Improving Chronic Illness Care: Capturing Daily Experiences of Academic Primary Care Teams. J Gen Intern Med. 2010;25(Suppl 4):581-585.

12) Sinsky CA, Willard-Grace R, Schutzbank AM, Sinsky TA, Margolius D, Bodenheimer T. In Search of Joy in Practice: A Report of 23 High-Functioning Primary Care Practices. Ann Fam Med. 2013;11:272-278.

13) Jortberg BT, Fernald DH, Dickinson LM, Coombs L, Deaner N, O'Neill C, deGruy F, Green L, Dickinson WP . Curriculum redesign for teaching the PCMH in Colorado Family Medicine Residency programs. Fam Med. 2014;46:11-18.

14) Dickinson WP. Residents as change agents in the transformation of primary care practices. Fam Med. 2010;42:469-470. 
367 15) Crosson FJ, Leu J, Roemer BM, Ross MN. Gaps in residency training should be addressed to 368 better prepare doctors for a twenty-first-century delivery system. Health Aff (Millwood). $369 \quad 2011 ; 30: 2142-2148$.

370 16) United States Department of Health and Human Services. Teaching Health Center Graduate 371 Medical Education. (http://bhpr.hrsa.gov/grants/teachinghealthcenters/html). Accessed Jaunary 17, 3722014.

373 17) United States Department of Health and Human Services. Teaching Health Center Graduate 374 Medical Education. (http://bhpr.hrsa.gov/grants/teachinghealthcenters/payments.html). Accessed 375 December 13, 2013.

376 18) Nutting PA, Dickinson WP, Dickinson LM, Nelson CC, King DK, Crabtree BF, Glasgow RE. Use 377 of chronic care model elements is associated with higher-quality care for diabetes.Ann Fam $378 \quad$ Med. 2007;5(1):14-20.

379 19) Nease DE, Nutting PA, Dickinson WP, Bonham AJ, Graham DG, Gallagher KM, Main DS. 380 Inducing sustainable improvement in depression care in primary care practices: A report from the 381 National Depression Management Leadership Initiative's Improving Depression Care Project. Joint 382 Commission Journal on Quality and Patient Safety 2008. 34(5):247-255. 383 384 385 386 387 388 389

20) Bidassie B, Davies ML, Stark R, Boushon B. VA Experience in Implementing Patient-Centered Medical Home Using a Breakthrough Series Collaborative. J Gen Intern Med. 2014;29(Suppl 2):563-571.

21) Luck J, Bowman C, York L, Midboe A, Taylor T, Gale R, Asch H. Multimethod Evaluation of the VA's Peer-to-Peer Toolkit for Patient-Centered Medical Home Implementation. J Gen Intern Med. 2014;Suppl 2:S572-578 
22) Friedberg MW, Schneider EC, Rosenthal MB, Volpp KG, Werner RM. Association between Participation in a Multipayer Medical Home Intervention and Changes in Quality, Utilization, and Costs of Care. JAMA. 2014;311:815-825.

23) Jackson GL, Powers BJ, Chatterjee R, Bettger JP, Kemper AR, Hasselblad V, Dolor RJ, Irvine RJ, Heidenfelder BL, Kendrick AS, Gray R, Williams JW. Improving patient care. The patient centered medical home. A Systematic Review. Ann Intern Med. 2013;158:169-178.

24) Hochman ME, Asch S, Jibilian A, Chaudry B, Ben-Ari R, Hsieh E, Berumen M, Mokhtari S, Raad M, Hicks E, Sanford C, Aguirre N, Tseng CH, Vangala S, Mangione CM, Goldstein DA. . Patientcentered medical home intervention at an Internal Medicine resident safety-net clinic. JAMA Intern Med. 2013;173:1694-1701.

25) Palamaner Subash Shantha G, Meade L, Thomas-Hemak L. Teaching Health Center Curriculum: A Promising Training Model to Meet the Demands of the Primary Care Physician Workforce. Talk Presented at the National Association of Community Health Centers Community Health Institute August 25, 2013. (http://meetings.nachc.com/wp-content/uploads/2013/06/2013). Accessed July $21,2013$. 
Table $\mathbf{1}$ (on next page)

Baseline Demographic Characteristics of 2011 THC and 2011 TR Residents

Baseline demographic comparisons between THC and TR residents 
2 Table 1: Baseline Demographic Characteristics of 2011 THC and 2011 TR Residents

\begin{tabular}{|c|c|c|c|}
\hline & 2011 THC Residents $(n=12)$ & 2011 TR Residents $(n=12)$ & P-value \\
\hline Age (yrs) & $34[5.5]$ & $31[3]$ & 0.008 \\
\hline Males- n (\%) & $6(50)$ & $7(58)$ & 1.000 \\
\hline Country of origin & & & 0.515 \\
\hline India- $\mathrm{n}(\%)$ & $6(50)$ & $7(58)$ & \\
\hline Egypt - n (\%) & $3(25)$ & $0(0)$ & \\
\hline $\mathrm{USA}-\mathrm{n}(\%)$ & $1(8)$ & $2(17)$ & \\
\hline China $-\mathrm{n}(\%)$ & $1(8)$ & $2(17)$ & \\
\hline Syria $-\mathrm{n}(\%)$ & $0(0)$ & $1(8)$ & \\
\hline Libya - n (\%) & $1(8)$ & $0(0)$ & \\
\hline Yrs. since medical school grad. (yrs) & $8(4)$ & $4(3.5)$ & 0.001 \\
\hline Prior residency training $-\mathrm{n}(\%)$ & $10(83)$ & $7(58)$ & 0.185 \\
\hline Advanced degrees $-\mathrm{n}(\%)$ & $3(25)$ & $5(42)$ & 0.333 \\
\hline Prior clinical experience $-\mathrm{n}(\%)$ & $12(100)$ & $11(92)$ & 0.500 \\
\hline Prior research experience $-\mathrm{n}(\%)$ & $7(58)$ & $8(67)$ & 0.500 \\
\hline
\end{tabular}

3 


\section{1}

Figure 1

KSA comparison of 2011 THC and 2011 TR Residents May 2012 and Nov 2012

\section{Figure 1}

\begin{tabular}{|c|c|c|c|c|}
\hline $\begin{array}{l}\text { PCMH } \\
\text { competencies }\end{array}$ & $\begin{array}{l}\text { Mean } \\
\text { Scores } \\
\text { (THC) }\end{array}$ & $\begin{array}{l}\text { Mean } \\
\text { Scores } \\
\text { (TR) }\end{array}$ & May 2012 & $\mathrm{MD}(95 \% \mathrm{Cl})$ \\
\hline $\begin{array}{l}\text { Care Coordination } \\
\text { Info System Support } \\
\text { Patient Centered Care } \\
\text { Population management } \\
\text { Quality Improvement } \\
\text { Self-Man Support } \\
\text { Team Approach } \\
\text { Mental Health Tx } \\
\text { Use of Guidelines }\end{array}$ & $\begin{array}{l}4.6 \\
4.4 \\
4.1 \\
4.5 \\
4.2 \\
4.4 \\
4.5 \\
4.9 \\
4.5\end{array}$ & $\begin{array}{l}4.0 \\
4.1 \\
4.3 \\
4.0 \\
4.1 \\
4.2 \\
4.3 \\
4.4 \\
4.3\end{array}$ & $\begin{array}{c}\square \\
+\square \\
\square \\
\square \\
\square\end{array}$ & $\begin{array}{l}0.57(0.19,0.95) \\
0.27(-0.14,0.68) \\
-0.24(-0.64,0.16) \\
0.58(0.23,0.93) \\
0.14(-0.22,0.50) \\
0.27(-0.04,0.58) \\
0.24(-0.11,0.59) \\
0.48(0.15,0.81) \\
0.16(-0.17,0.49)\end{array}$ \\
\hline
\end{tabular}

\begin{tabular}{|c|c|c|c|c|}
\hline $\begin{array}{l}\text { PCMH } \\
\text { Competencies }\end{array}$ & $\begin{array}{l}\text { Mean } \\
\text { Scores } \\
\text { (THC) }\end{array}$ & $\begin{array}{l}\text { Mean } \\
\text { Scores } \\
\text { (TR) }\end{array}$ & November 2012 & $\mathrm{MD}(95 \% \mathrm{Cl})$ \\
\hline $\begin{array}{l}\text { Care Coordination } \\
\text { Info System Support } \\
\text { Patient Centered Care } \\
\text { Population management } \\
\text { Quality Improvement } \\
\text { Self-Man Support } \\
\text { Team Approach } \\
\text { Mental Health Tx } \\
\text { Use of Guidelines }\end{array}$ & $\begin{array}{l}4.3 \\
3.9 \\
4.2 \\
4.5 \\
4.6 \\
4.6 \\
4.5 \\
4.8 \\
4.4\end{array}$ & $\begin{array}{l}4.2 \\
4.2 \\
4.2 \\
4.1 \\
4.1 \\
4.3 \\
4.0 \\
4.4 \\
4.2\end{array}$ & $\begin{array}{l}\overrightarrow{5} \\
\square \\
\square \\
\square\end{array}$ & $\begin{array}{l}0.10(-0.47,0.67) \\
-0.30(-0.80,0.20) \\
0.00(-0.64,0.64) \\
0.40(-0.15,0.95) \\
0.50(-0.14,1.14) \\
0.30(-0.11,0.71) \\
0.50(-0.05,1.05) \\
0.40(-0.12,0.92) \\
0.20(-0.37,0.77)\end{array}$ \\
\hline
\end{tabular}

PCMH Competencies Comparison of 2011 THC and 2011 TR Residents May 2012 and Nov 2012 
Table 2 (on next page)

Longitudinal KSA 2011 THC Residents Comparison to Baseline

Longitudinal KSA comparisons for THC residents at the pre-defined time points compared to their baseline 
2 Table 2: Longitudinal KSA 2011 THC Residents Comparison to Baseline

\begin{tabular}{|l|c|c|c|c|c|c|c|}
\hline \multicolumn{1}{|c|}{ Competency } & Nov 2011 n=12 & May 2012 n=12 & P value & Nov 2012 n=12 & P-value & May 2014 n=11 & P value \\
\hline Care Coordination & $4.0(3.5-4.5)$ & $4.7(4.3-5.0)$ & 0.039 & $4.3(3.9-4.7)$ & 0.106 & $4.7(4.4-4.9)$ & 0.031 \\
\hline Info System Support & $3.5(3.2-3.8)$ & $4.4(4.0-4.7)$ & 0.001 & $3.9(3.7-4.2)$ & 0.113 & $4.5(4.2-4.8)$ & 0.001 \\
\hline Patient Centered Care & $4.2(3.7-4.7)$ & $4.1(3.7-4.5)$ & 0.283 & $4.2(3.6-4.8)$ & 0.558 & $4.6(4.3-4.9)$ & 0.092 \\
\hline Population Management & $3.8(3.4-4.2)$ & $4.6(4.1-4.9)$ & 0.001 & $4.5(4.1-4.9)$ & 0.022 & $4.6(4.3-4.9)$ & 0.028 \\
\hline Quality Improvement & $4.0(3.6-4.5)$ & $4.3(3.9-4.7)$ & 0.094 & $4.5(4.2-4.9)$ & 0.039 & $4.6(4.3-4.9)$ & 0.037 \\
\hline Self-Man Support & $4.1(3.5-4.6)$ & $4.5(4.1-4.8)$ & 0.021 & $4.5(4.3-4.9)$ & 0.047 & $4.5(4.2-4.8)$ & 0.057 \\
\hline Team Approach & $3.8(3.4-4.3)$ & $4.6(4.3-5.0)$ & 0.001 & $4.5(4.2-4.9)$ & 0.001 & $4.4(4.0-4.7)$ & 0.016 \\
\hline Mental Health Tx & $4.4(3.8-4.9)$ & $4.9(4.5-5.0)$ & 0.041 & $4.7(4.4-5.0)$ & 0.296 & $4.6(4.3-4.9)$ & 0.314 \\
\hline Use of Guidelines & $4.2(3.7-4.7)$ & $4.5(4.2-4.9)$ & 0.089 & $4.4(4.1-4.8)$ & 0.217 & $4.6(4.3-4.9)$ & 0.100 \\
\hline
\end{tabular}

3 
Table 3(on next page)

Longitudinal KSA2011 TR Residents Comparison to Baseline

Longitudinal KSA comparisons for TR residents at pre-defined time points compared to their baseline 
2 Table 3: Longitudinal KSA2011 TR Residents Comparison to Baseline

\begin{tabular}{|l|c|c|c|c|c|c|c|}
\hline \multicolumn{1}{|c|}{ Competency } & Nov 2011 n=12 & May 2012 n=12 & P value & Nov 2012 n=12 & P-value & May 2014 n=12 & P value \\
\hline Care Coordination & $4.1(3.5-4.7)$ & $4.1(3.6-4.5)$ & 0.833 & $4.2(3.7-4.6)$ & 0.625 & $4.3(3.7-4.9)$ & 0.225 \\
\hline Info System Support & $3.9(3.0-4.0)$ & $4.2(3.8-4.6)$ & 0.068 & $4.2(3.6-4.7)$ & 0.109 & $4.3(3.6-4.9)$ & 0.053 \\
\hline Patient Centered Care & $4.3(3.8-4.7)$ & $4.4(4.0-4.7)$ & 0.532 & $4.2(3.8-4.6)$ & 0.812 & $4.4(3.5-4.9)$ & 0.719 \\
\hline Population Management & $3.6(3.0-4.3)$ & $4.0(3.5-4.3)$ & 0.094 & $4.1(3.6-4.6)$ & 0.077 & $4.2(3.5-4.8)$ & 0.021 \\
\hline Quality Improvement & $3.8(3.1-4.5)$ & $4.1(3.5-4.5)$ & 0.561 & $4.1(3.5-4.8)$ & 0.104 & $4.3(3.7-4.8)$ & 0.033 \\
\hline Self-Man Support & $4.0(3.5-4.3)$ & $4.2(3.5-4.5)$ & 0.735 & $4.3(4.0-4.7)$ & 0.113 & $4.5(4.0-5.0)$ & 0.017 \\
\hline Team Approach & $3.8(3.5-4.5)$ & $4.3(4.0-4.9)$ & 0.199 & $4.0(3.5-4.6)$ & 0.784 & $4.4(3.9-5.0)$ & 0.038 \\
\hline Mental Health Tx & $4.0(3.3-4.7)$ & $4.4(4.0-4.8)$ & 0.187 & $4.4(4.0-4.8)$ & 0.172 & $4.5(4.1-5.0)$ & 0.036 \\
\hline Use of Guidelines & $4.2(3.7-4.5)$ & $4.4(4.0-4.8)$ & 0.116 & $4.2(3.7-4.7)$ & 0.978 & $4.5(4.0-4.9)$ & 0.136 \\
\hline
\end{tabular}

3 


\section{Table 4(on next page)}

KSA compared between THC residents $(n=12)$ and TR Residents $(n=12)$

KSA comparisons between TR and THC residents at pre-defined time points 
2 Table 4: KSA compared between THC residents $(n=12)$ and TR Residents $(n=12)$

\begin{tabular}{|c|c|c|c|c|c|c|c|c|c|}
\hline & \multicolumn{3}{|c|}{ November 2011} & \multicolumn{3}{|c|}{ May 2012} & \multicolumn{3}{|c|}{ November 2012} \\
\hline & THC & TR & P-value & THC & TR & P-value & THC & TR & P-value \\
\hline Care Coordination & $4.0(3.5-4.5)$ & $4.1(3.5-4.7)$ & 0.428 & $4.7(4.3-5.0)$ & $4.1(3.6-4.5)$ & 0.025 & $4.3(3.9-4.7)$ & $4.2(3.7-4.6)$ & 0.660 \\
\hline Info System Support & $3.5(3.2-3.8)$ & $3.9(3.0-4.0)$ & 0.107 & $4.4(4.0-4.7)$ & $4.2(3.8-4.6)$ & 0.177 & $3.9(3.7-4.2)$ & $4.2(3.6-4.7)$ & 0.082 \\
\hline Patient Centered Care & $4.2(3.7-4.7)$ & $4.3(3.8-4.7)$ & 0.382 & $4.1(3.7-4.5)$ & $4.4(4.0-4.7)$ & 0.392 & $4.2(3.6-4.8)$ & $4.2(3.8-4.6)$ & 0.537 \\
\hline Population Management & $3.8(3.4-4.2)$ & $3.6(3.0-4.3)$ & 0.173 & $4.6(4.1-4.9)$ & $4.0(3.5-4.3)$ & 0.036 & $4.5(4.1-4.9)$ & $4.1(3.6-4.6)$ & 0.115 \\
\hline Quality Improvement & $4.0(3.6-4.5)$ & $3.8(3.1-4.5)$ & 0.225 & $4.3(3.9-4.7)$ & $4.1(3.5-4.5)$ & 0.091 & $4.5(4.2-4.9)$ & $4.1(3.5-4.8)$ & 0.210 \\
\hline Self-Man Support & $4.1(3.5-4.6)$ & $4.0(3.5-4.3)$ & 0.491 & $4.5(4.1-4.8)$ & $4.2(3.5-4.5)$ & 0.047 & $4.5(4.3-4.9)$ & $4.3(4.0-4.7)$ & 0.307 \\
\hline Team Approach & $3.8(3.4-4.3)$ & $3.8(3.5-4.5)$ & 0.651 & $4.6(4.3-5.0)$ & $4.3(4.0-4.9)$ & 0.039 & $4.5(4.2-4.9)$ & $4.0(3.5-4.6)$ & 0.137 \\
\hline Mental Health Tx & $4.4(3.8-4.9)$ & $4.0(3.3-4.7)$ & 0.251 & $4.9(4.5-5.0)$ & $4.4(4.0-4.8)$ & 0.163 & $4.7(4.4-5.1)$ & $4.4(4.0-4.8)$ & 0.126 \\
\hline Use of Guidelines & $4.2(3.7-4.7)$ & $4.2(3.7-4.5)$ & 0.815 & $4.5(4.2-4.9)$ & $4.4(4.0-4.8)$ & 0.711 & $4.4(4.1-4.8)$ & $4.2(3.7-4.7)$ & 0.534 \\
\hline \multicolumn{10}{|c|}{ May 2014} \\
\hline & \multicolumn{3}{|c|}{ THC } & \multicolumn{3}{|c|}{ TR } & \multicolumn{2}{|r|}{$P$ value } & \\
\hline Care Coordination & \multicolumn{3}{|c|}{$4.7(4.4-4.9)$} & \multicolumn{3}{|c|}{$4.3(3.7-4.9)$} & \multicolumn{3}{|c|}{0.268} \\
\hline Info System Support & \multicolumn{3}{|c|}{$4.5(4.2-4.8)$} & \multicolumn{3}{|c|}{$4.3(3.6-4.9)$} & \multicolumn{3}{|c|}{0.811} \\
\hline Patient Centered Care & \multicolumn{3}{|c|}{$4.6(4.3-4.9)$} & \multicolumn{3}{|c|}{$4.4(3.5-4.9)$} & \multicolumn{3}{|c|}{0.515} \\
\hline Population Management & \multicolumn{3}{|c|}{$4.6(4.3-4.9)$} & \multicolumn{3}{|c|}{$4.2(3.5-4.8)$} & \multicolumn{3}{|c|}{0.297} \\
\hline Quality Improvement & \multicolumn{3}{|c|}{$4.6(4.3-4.9)$} & \multicolumn{3}{|c|}{$4.3(3.7-4.8)$} & \multicolumn{3}{|c|}{0.319} \\
\hline Self-Man Support & \multicolumn{3}{|c|}{$4.5(4.2-4.8)$} & \multicolumn{3}{|c|}{$4.5(4.0-5.0)$} & \multicolumn{3}{|c|}{0.372} \\
\hline Team Approach & \multicolumn{3}{|c|}{$4.4(4.0-4.7)$} & \multicolumn{3}{|c|}{$4.4(3.9-5.0)$} & \multicolumn{3}{|c|}{0.382} \\
\hline Mental Health Tx & \multirow{2}{*}{\multicolumn{3}{|c|}{$4.6(4.3-4.9)$}} & \multirow{2}{*}{\multicolumn{3}{|c|}{$4.5(4.1-5.0)$}} & \multicolumn{3}{|c|}{0.560} \\
\hline Use of Guidelines & & & & & & & & 0.502 & \\
\hline
\end{tabular}

